\title{
ANALISIS KINERJA FASILITAS OPERASI PERLINTASAN SEBIDANG (STUDI PADA RESORT 4.6 SMT)
}

\author{
Mariana Diah Puspitasari, Email : mariana@ppi.ac.id \\ Prodi Teknologi Elektro Perkeretaapian, Politeknik Perkeretaapian Indonesia Madiun
}

\begin{abstract}
ABSTRAK
PT Kereta Api Indonesia (KAI) selama tahun 2019 dan 2018 menghitung telah terjadi 655 kecelakaan pada perlintasan kereta api sebidang. Kecelakaan sering terjadi di daerah yang lalu lintasnya padat seperti di Resort Sinyal Telekomunikasi 4.6 SMT. Sehingga peneliti melakukan riset agar mengetahui kinerja fasilitas operasi perkeretaapian di bawah naungan Resort 4.6 SMT serta persepsi masyarakat terhadap kinerjanya. Peneliti menggunakan sound level meter untuk mengukur tingkat kekerasan suara sirine JPL pada lokasi penelitian. Selanjutnya dibandingkan dengan standart yang diatur dalam Peraturan Menteri Perhubungan Nomor 44 Tahun 2018. Lalu diuji menggunakan Anova untuk mengetahui apakah mean populasi akan bernilai sama dengan menggunakan data dari masing-masing populasi. Selanjutnya dilakukan wawancara tidak terstuktur untuk mendengar persepsi pengguna jalan pada kinerja fasilitas operasi pada JPL yang menjadi obyek penelitian. Hasil penelitian menunjukkan kelima JPL yang menjadi obyek penelitian, level kekerasan suara sirinenya di bawah standar yang ditetapkan. Sebaliknya lampu silang datar berkinerja baik. Sedangkan persepsi masyarakat untuk fasilitas operasi pada JPL menilai berfungsi dengan baik.
\end{abstract}

\section{Kata kunci: Jalur Perlintasan Langsung, Fasilitas Operasi, Kereta Api}

\section{ABSTRACT}

PT Kereta Api Indonesia (KAI) during 2019 and 2018 calculated that there had been 655 accidents at level rail crossings. Accidents often occur in high traffic areas such as the Telecommunication Signal Resort 4.6 SMT. So the researchers conducted research in order to find out the performance of the railway operating facilities under the auspices of the Telecommunication Signal Resort 4.6 SMT as well as public perceptions of its performance. Researchers used a sound level meter to measure the loudness level of the level rail crossings siren sound at the research location. Furthermore, it is compared with the standards stipulated in the Minister of Transportation Regulation Number 44 of 2018. Then tested using Anova to find out whether the population mean will be of the same value using data from each population. Furthermore, an unstructured interview was conducted to hear the perceptions of road users on the performance of the operational facilities at level rail crossings which became the research object. The results showed that the five level rail crossings which were the object of the study had the loudness level of the siren sound below the set standard. In contrast, flat cross lights perform well. Meanwhile, the public perception of the operational facilities at level rail crossings is that they are functioning well.

Keywords: level rail crossing, operating facility, railway 


\section{PENDAHULUAN}

\subsection{Latar Belakang}

PT Kereta Api Indonesia (KAI) selama tahun 2019 menghitung setidaknya telah terjadi 260 kali kecelakaan yang mengakibatkan 76 nyawa melayang pada perlintasan kereta api (KA) sebidang. Lalu tahun sebelumnya, terjadi 395 kecelakaan yang menyebabkan 245 orang luka berat sampai meninggal dunia. Total, selama dua tahun telah terjadi 655 kecelakaan (Wahyudi, 2019).

Senada dengan hal tersebut, Sekretaris Jenderal Kementerian Perhubungan, Djoko Sasono, mengungkapkan bahwa penyebab tingginya kecelakaan di perlintasan KA karena beberapa pengendara tidak mematuhi rambu yang dipasang dekat perlintasan. Sehingga perlintasan sebidang KA menjadi titik rawan terjadinya pelanggaran lalu lintas, karena banyak pengendara yang menerobos palang pintu sebagai tanda. Padahal KAI mencatat saat ini masih terdapat 1.223 perlintasan kereta sebidang yang resmi, dan yang tidak legal lebih banyak yakni mencapai 3.419. Sedangkan perlintasan sebidang berupaf lyover dan underpass berjumlah 349 titik. Di lain sisi palang pintu perlintasan merupakan salah satu alat penting untuk keamanan perjalanan KA.

\section{Gambar 1 JPL 5 Kaligawe yang 3 Kali} Tertabrak dalam Satu Tahun Terakhir

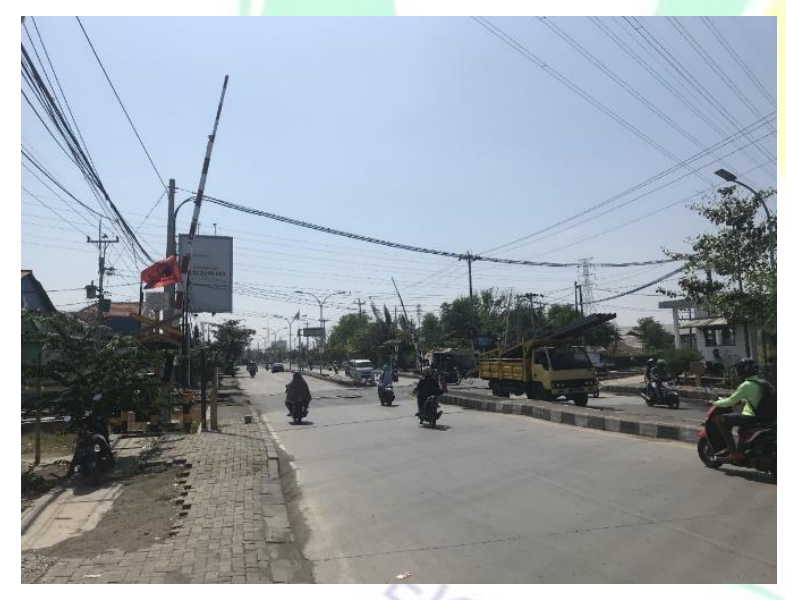

Sumber: Dokumentasi Lapang, 2020

Seperti halnya di Resort Sinyal Telekomunikasi 4.6 SMT. Dimana mempunyai aset
12 Jalur Perlintasan Langsung (JPL) dan bertanggung jawab untuk merawat dan memelihara JPL tersebut supaya berfungsi sebagaimana mestinya. Selain kuantitas yang memang banyak, kondisi lalu lintas di Kota Semarang yang merupakan jalan nasional menuju ke Jakarta dan Surabaya mengakibatkan 7 kali lengan JPL patah akibat tertabrak pengendara jalan raya selama setahun terakhir. 3 kali terjadi di JPL Kaligawe, 1 kali di JPL Layur, 1 kali di JPL Hasanudin, 1 kali di JPL Kokrosono, dan 1 Kali di JPL BLPT.

\subsection{Rumusan Masalah}

Berangkat dari hal diatas, ada dua permasalahan yang coba dijawab yaitu, bagaimanakah kinerja fasilitas operasi pada JPL di bawah Resort 4.6 SMT yang dalam satu tahun terakhir patah karena tertabrak? Serta bagaimanakah persepsi pengguna jalan terhadap kinerja fasilitas operasi pada JPL di bawah Resort 4.6 SMT yang dalam satu tahun terakhir patah karena tertabrak?

\section{TINJAUAN PUSTAKA}

\subsection{Penelitian Terdahulu}

Penelitian ini menggunakan beberapa penilitian terdahulu yang terkait dengan topik bahasan penelitian ini. Salah satunya penelitian Anza Hana Wafiroh (2013). Penelitian yang bertujuan untuk mengetahui tingkat kebisingan yang diterima oleh lingkungan sekolah yang diakibatkan dari kebisingan lalu lintas jalan raya. Dengan mengukur tingkat kebisingan pada tiga lokasi di lingkungan SMPN 2 Jember yaitu lokasi 1 pada ruang 1, lokasi 2 pada ruang 2 yang mewakili ruang 2, 3 dan 4 , lokasi 3 pada ruang 43 yang mewakili ruang 42 dan 43 dengan masing-masing lokasi dibagi menjadi tiga titik pengambilan data.

Untuk pengambilan data pembanding, yaitu banyaknya jumlah kendaraan dilakukan dengan menghitung langsung jumlah kendaraan yang melewati jalan raya lingkungan sekolah. Menggunakan data pembanding, karena sumber kebisingan yang diukur adalah sumber kebisingan lalu lintas jalan raya. Besar jumlah kendaraan tersebut digunakan sebagai acuan bahwa kebisingan yang dihasilkan pada setiap jamnya dapat 
mendekati atau hampir sama antara jam pertama, kedua dan jam berikutnya. Besar jumlah kendaraan pada setiap jamnya rata-rata 10.711 kendaraan. Hasil dari pengambilan data tingkat kebisingan di semua lokasi kemudian dihitung dan digrafikkan serta dianalisis.

\subsection{Perkeretaapian: Definisi dan Tujuannya}

Pengertian Perkeretaapian dalam Undang Undang Republik Indonesia No. 23 tahun 2007 tentang Perkeretaapian adalah satu kesatuan sistem yang terdiri atas prasarana, sarana, dan sumber daya manusia, serta norma, kriteria, persyaratan, dan prosedur untuk penyelenggaraan transportasi kereta api. Sedangkan kererta api sendiri merupakan sarana perkeretaapian dengan tenaga gerak, baik berjalan sendiri maupun dirangkaikan dengan sarana perkeretaapian lainnya, yang akan ataupun sedang bergerak di jalan rel yang terkait dengan perjalanan kereta api.

Pasal 3 Undang - Undang Republik Indonesia No. 23 tahun 2007 tentang Perkeretaapian berisi tujuan diselenggarakannya perkeretaapian yaitu untuk memperlancar perpindahan orang dan/atau barang secara massal dengan selamat, aman, nyaman, cepat dan lancar, tepat, tertib, dan teratur, efisien, serta menunjang pemerataan, pertumbuhan, stabilitas, pendorong, dan penggerak pembangunan nasional.

\subsection{Peraturan Menteri Perhubungan Nomor PM 44 Tahun 2018 tentang Persyaratan Teknis Peralatan Persinyalan Perkeretaapian}

Peralatan pengamanan perlintasan sebidang berfungsi untuk mengamankan perjalanan kereta api pada waktu melewati perlintasan sebidang dari pengguna jalan raya. Persyaratan material yang harus dipenuhi pada pengamanan perlintasan sebidang diantaranya:

a) dilengkapi dengan sirine dengan karakteristik sebagai berikut:

1) daya yang masuk maksimum $30 \mathrm{~W}$ atau sesuai dengan desain/perhitungan;

2) frekuensi respon $400 \mathrm{~Hz}-4000 \mathrm{~Hz}$ atau sesuai dengan desain/perhitungan;

3) keras suara $115 \mathrm{db}$ (jarak $1 \mathrm{~m}$ ) atau sesuai dengan desain/perhitungan; dan
4) impedansi pengeras suara $16 \mathrm{ohm} \pm 15 \%$ (1 $\mathrm{kHz}$ ) atau sesuai dengan desain/perhitungan.

b) pintu terbuat dari kayu atau fiber atau bahan lain sesuai dengan desain dan standar;

c) penggerak pintu berupa motor DC atau sesuai dengan desain/perhitungan;

d) palang pintu warna putih dan merah pendar cahaya; dan

e) sumber daya listrik dari PLN atau sumber lain dengan tegangan $220 \mathrm{~V} 50 \mathrm{~Hz}$ atau dengan tegangan baterai.

Gambar 2 Desain Pintu Perlintasan Kereta Api

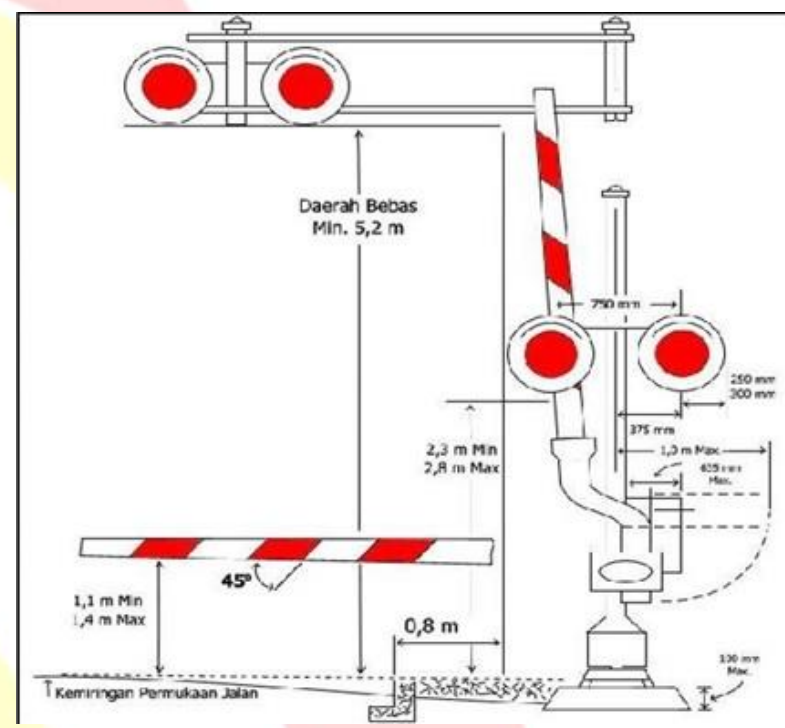

Sumber : SK.770/KA.401/DRJD/2005

\subsection{Bunyi dan Kebisingan}

Bunyi merupakan gelombang mekanik jenis longitudinal yang merambat dan sumbernya berupa benda yang bergetar. Bunyi bisa didengar sebab getaran benda sebagai sumber bunyi menggetarkan udara di sekitar dan melalui medium udara bunyi merambat sampai ke gendang telinga, sebenarnya merupakan variasi tekanan udara secara periodik di sepanjang lintasan perambatannya. Tekanan udara periodik inilah yang menggetarkan selaput gendang telinga. Bunyi yang dapat didengar manusia berada pada kawasan frekuensi pendengaran, yaitu antara $20 \mathrm{~Hz}$ sampai dengan $20 \mathrm{kHz}$ (Soedojo, 2004). Suara diatas $20 \mathrm{kHz}$ disebut ultrasonic sedang di bawah $20 \mathrm{~Hz}$ disebut infrasonik.

Bising dan bunyi kadangkala dapat diartikan sama, yang membedakannya adalah bahwa bising 
adalah bunyi yang tidak diinginkan. Di bidang ilmu murni dan teknik, bising adalah komponen yang tidak diinginkan yang mengaburkan sinyal. Dapat juga diambil pengertian bahwa semua bunyi yang mengalihkan perhatian, mengganggu, atau berbahaya bagi kegiatan sehari-hari (kerja, istirahat, hiburan, atau belajar) dianggap bising (Su'udi, 2010).

\subsection{Suara: Alat Pengukur, Cara Mengukurnya, dan Hal yang Mempengaruhi}

Alat pengukur yang digunakan dalam pengukuran suara maupun kebisingan seperti dikutip dari Handbook of Occupational Safety and Health (1999) adalah Sound Level Meter (SLM). Alat ini digunakan untuk mengukur kebisingan di lingkungan kerja. Ada tiga cara atau metode pengukuran akibat kebisingan di lokasi kerja menurut Harahap (2016):

a) Pengukuran dengan titik sampling

Pengukuran ini dilakukan bila kebisingan diduga melebihi ambang batas hanya pada satu atau beberapa lokasi saja.

b) Pengukuran dengan peta kontur

Pengukuran dengan membuat peta kontur sangat bermanfaat dalam mengukur kebisingan, karena peta tersebut dapat menentukan gambar tentang kondisi kebisingan dalam cakupan area.

c) Pengukuran dengan Grid

Untuk mengukur dengan Grid adalah dengan membuat contoh data kebisingan pada lokasi yang diinginkan. Titik- titik sampling harus dibuat dengan jarak interval yang sama diseluruh lokasi.

Beberapa hal yang mempengaruhi pengukuran kebisingan, diantaranya (Tambunan, 2005):

a) Background noise kebisingan

b) Angin

c) Kelembaban

d) Suhu

e) Tekanan Udara

f) Getaran

g) Medan magnet

\section{METODOLOGI PENELITIAN}

Jenis penelitian yang digunakan adalah penelitian gabungan antara kuantitatif dan kualitatif untuk menjawab rumusan masalah. Penelitian kualitatif ialah prosedur penelitian yang menghasilkan data deskriptif berupa kata-kata tertulis atau lisan dari orang-orang dan perilaku yang diamati (Bodgan dan Taylor dalam Barowi dan Suwandi, 2009: 21). Sedangkan Metode penelitian kuantitatif merupakan suatu cara yang digunakan untuk menjawab masalah penelitian yang berkaitan dengan data berupa angka dan program statistik (Wahidmurni, 2017).

Dalam penelitian ini menggunakan data primer dan data sekunder. Menurut Hasan (2002: 82) data primer ialah data yang diperoleh atau dikumpulkan langsung di lapangan oleh orang yang melakukan penelitian atau yang bersangkutan yang memerlukannya. Data primer yang digunakan adalah data kinerja fasilitas operasi pada JPL di bawah Resort 4.6 SMT yang patah tertabrak dalam setahun terakhir yaitu JPL 5 Kaligawe, JPL 1B Layur, JPL Hasanudin, JPL Kokrosono, dan JPL BLPT khususnya alat peringatan dini bagi pengguna jalan. Yaitu pengeras suara, serta lampu peringatan. Selain itu data primer yang digunakan adalah persepsi pengguna jalan.

Sedangkan data sekunder adalah data yang diperoleh atau dikumpulkan oleh orang yang melakukan penelitian dari sumber-sumber yang telah ada (Hasan, 2002: 58). Data ini digunakan untuk mendukung informasi primer yang telah diperoleh yaitu dari bahan pustaka, literatur, penelitian terdahulu, buku, dan lain sebagainya. Pada penelitian ini, data sekunder yang digunakan diantaranya data yang dirilis oleh pemangku kebijakan, jurnal ilmiah, penelitian terdahulu, serta informasi pendukung lainnya.

Untuk mendapatkan data, metode pengumpulan data yang peneliti lakukan adalah observasi, dokumentasi, dan wawancara. Observasi dan dokumentasi yang dilakukan adalah pengukuran sirine pada JPL di bawah Resort 4.6 SMT yang patah tertabrak dalam setahun terakhir yaitu JPL 5 Kaligawe, JPL 1B Layur, JPL Hasanudin, JPL Kokrosono, dan JPL BLPT dilakukan beberapa kali dalam pengambilan data guna keakuratan untuk dibandingkan dengan standart sesuai dengan peraturan yang berlaku. 


\section{Gambar 3 Sound Level Meter yang Digunakan Untuk Mengukur Sirine}

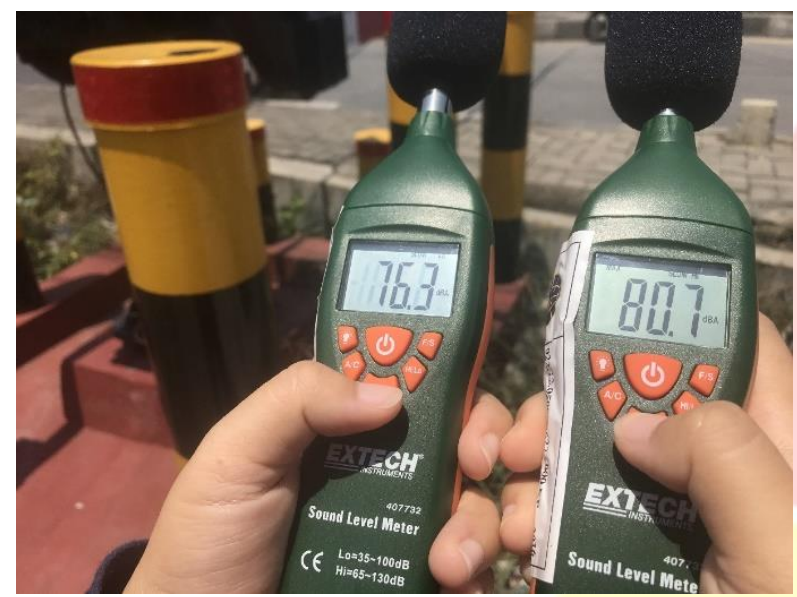

Untuk mengukur sirine, peneliti menggunakan sound level meter seperti gambar diatas. Selanjutnya hasil dari perhitungan ini akan ditabulasi lalu dianalisa menggunakan Analisa Varians (ANOVA). Menurut Harinaldi (2005:192) analisis varians adalah suatu teknik statistik yang memungkinkan kita untuk mengetahui apakah dua atau lebih mean populasi akan bernilai sama dengan menggunakan data dari sampel-sampel masingmasing populasi. Analisis varians lebih efektif digunakan menguji tiga atau lebih populasi. Untuk itu analisis varians ini sangat tepat digunakan untuk mengolah hasil pengamatan kekerasan suara sirine di lokasi penelitian yaitu JPL 5 Kaligawe, JPL 1B Layur, JPL Hasanudin, JPL Kokrosono, dan JPL BLPT.

Dalam operasionalnya, peneliti menggunakan SPSS 21 untuk mengolah data. Hasil dari analisa ini akan digunakan untuk menjawab rumusan masalah pertama. Sedangkan untuk menjawab rumusan masalah kedua, hasil wawancara tidak terstruktur dianalisa dengan beberapa tahap yaitu reduksi data, penyajian data, penarikan simpulan serta triangulasi.

\section{HASIL DAN PEMBAHASAN}

Peneliti melakukan observasi pada JPL di bawah Resort 4.6 SMT yang patah tertabrak dalam setahun terakhir yaitu JPL 5 Kaligawe, JPL 1B Layur, JPL Hasanudin, JPL Kokrosono, dan JPL BLPT.

\section{Gambar 4 PJL 5 Kaligawe Resort 4.6 SMT}

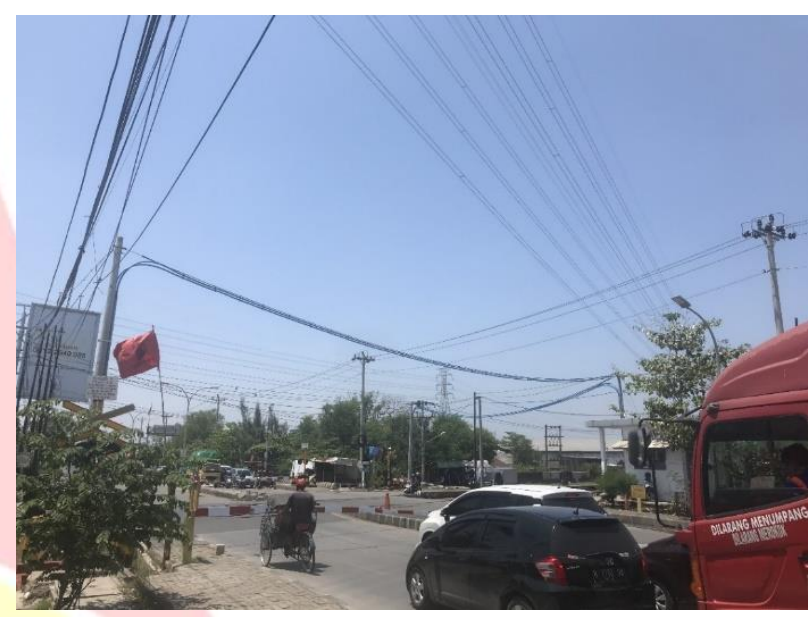

Sumber: Dokumentasi Lapang, 2020

\subsection{Kinerja Fasilitas Operasi Perlintasan Sebidang}

Dalam sebuah perlintasan sebidang, Peraturan Menteri Perhubungan Nomor PM 44 Tahun 2018 tentang Persyaratan Teknis Peralatan Persinyalan Perkeretaapian mengatur jenis sekaligus persyaratan operasinya. Namun, penelitian ini hanya fokus pada peringatan dini untuk pengguna jalan raya. Dimana diatur bahwa peringatan ini berupa pengeras suara/audible alarm serta lampu silang datar. Keberadaan peringatan untuk pengguna jalan raya ini berfungsi untuk memberikan keamanan pada perjalanan baik bagi pengguna jalan maupun kereta api.

\subsubsection{Peringatan Dini Untuk Pengguna: Lampu Silang Datar}

Dari observasi yang dilakukan, keberadaan lampu pada perlintasan sebidang kereta api ini telah terpasang sesuai dengan persyaratan pemasangan yang telah diatur oleh Peraturan Menteri Perhubungan Nomor PM 44 Tahun 2018 tentang Persyaratan Teknis Peralatan Persinyalan Perkeretaapian. 


\section{Gambar 5 Lampu Silang Datar pada Pintu Perlintasan Sebidang}

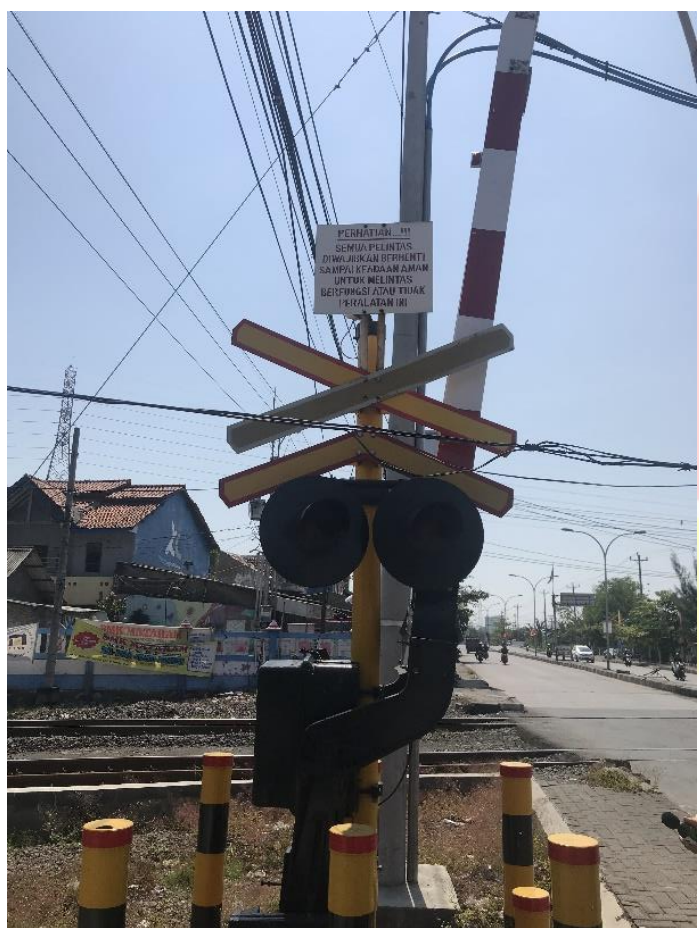

Sumber: Dokumentasi Lapang, 2020

Pada gambar diatas, menunjukkan bahwa lampu telah terpasang dengan posisi horizontal dan dipasang pada tiang statif dengan struktur yang kokoh. Lampu ini berjumlah dua buah di tiap pintu perlintasan. Lampu ini akan menyala saat pintu perlintasan akan menutup pada waktu kereta api akan lewat. Pada periode observasi, peneliti mengamati lampu ini bekerja dengan baik. Menyala dan dapat dilihat dengan jelas oleh para pengguna jalan. Sehingga dapat menjalankan fungsinya sebagai peringatan dini bagi pengguna jalan.

\subsubsection{Kinerja Sirine Pada JPL 5 Kaligawe, JPL 1B Layur, JPL Hasanudin, JPL Kokrosono, dan JPL BLPT di Bawah Resort 4.6 SMT}

Selain lampu yang harus menyala dengan baik, pada pintu perlintasan sebidang harus memiliki peringatan dini untuk pengguna jalan raya berupa pengeras suara/audible alarm. Pengeras suara ini harus ditempatkan pada bagian atas pintu perlintasan.

Selain itu, sirine sebagai peringatan dini kepada pengguna jalan harus memenuhi persyaratan teknis yang diatur oleh Peraturan Menteri Perhubungan Nomor PM 44 Tahun 2018 tentang Persyaratan Teknis Peralatan Persinyalan Perkeretaapian.
Dalam peraturan ini mensyaratkan sirine harus memiliki tingkat keras suara $115 \mathrm{db}$ (jarak $1 \mathrm{~m}$ ) atau sesuai dengan desain/perhitungan. Peneliti melakukan observasi pada siang dan malam hari untuk mengukur tingkat kekerasan suara sirine di JPL 5 Kaligawe, JPL 1B Layur, JPL Hasanudin, JPL Kokrosono, dan JPL BLPT di Bawah Resort 4.6 SMT.

Dari hasil observasi di lokasi penelitian, dihasilkan data hasil perhitungan pada JPL 5 Kaligawe menunjukkan angka perhitungan hasil pengujian suara sirine di bawah standar. Secara ratarata sebesar 83,7 db. Sama halnya dengan JPL 5 Kaligawe, hasil perhitungan pada JPL 1B Layur juga menunjukkan angka perhitungan hasil pengujian suara sirine di bawah standar. Secara ratarata sebesar $83,1 \mathrm{db}$.

Sama halnya dengan JPL sebelumnya, hasil perhitungan pada JPL Hasanudin juga menunjukkan angka perhitungan hasil pengujian suara sirine di bawah standar. Secara rata-rata sebesar 83,4 db. Untuk hasil perhitungan pada JPL BLPT juga menunjukkan angka perhitungan hasil pengujian suara sirine di bawah standar. Secara rata-rata sebesar 83,5 db. Sedangkan hasil perhitungan pada JPL Kokrosono juga menunjukkan angka perhitungan hasil pengujian suara sirine di bawah standar. Secara rata-rata sebesar $83,4 \mathrm{db}$ sama dengan JPL Hasanudin.

Selanjutnya hasil tabulasi data diatas diuji apakah tiap JPL memiliki varians yang sama menggunakan Test of Homogeneity of Variances. Uji ini dilakukan menggunakan SPSS 21 dan menghasilkan hasil uji yang bisa dilihat pada tabel di bawah.

\section{Tabel 1 Test of Homogeneity of Variances} HASILUJI

\begin{tabular}{|r|r|r|r|}
\hline $\begin{array}{c}\text { Levene } \\
\text { Statistic }\end{array}$ & df1 & df2 & \multicolumn{1}{|c|}{ Sig. } \\
\hline .487 & & 131 & \\
\hline
\end{tabular}

Sumber: Data Lapang Diolah, 2020

Dari tabel test of homogeneity of variance yang menguji hipotesis:

$H_{0}: \sigma_{1}^{2}=\sigma_{2}^{2}=\sigma_{3}^{2}=\sigma_{4}^{2}=\sigma_{5}^{2}$ 
$\mathrm{H}_{1}: \sigma_{1}^{2} \neq \sigma_{2}^{2} \neq \sigma_{3}^{2} \neq \sigma_{4}^{2} \neq \sigma_{5}^{2}$

Dimana:

$\sigma_{1}^{2}=$ varians dari populasi Sirine JPL 5 Kaligawe

$\sigma_{2}{ }^{2}=$ varians dari populasi Sirine JPL 1B Layur

$\sigma_{3}{ }^{2}=$ varians dari populasi Sirine JPL Hasanudin

$\sigma_{4}{ }^{2}=$ varians dari populasi Sirine JPL BLPT

$\sigma_{5}^{2}=$ varians dari populasi Sirine JPL Kokrosono

Hasil uji memberikan nilai $\mathbf{P}$-value $=\mathbf{0 . 7 4 5}$ yang lebih besar dari $\boldsymbol{\alpha}=\mathbf{0 , 0 5}$ sehingga menurut Uyanto (2009) dapat ditarik kesimpulan $H_{0}: \sigma_{1}^{2}=\sigma_{2}{ }^{2}=\sigma_{3}{ }^{2}$ $=\sigma_{4}{ }^{2}=\sigma_{5}{ }^{2}$ tidak dapat ditolak. Artinya kelima kelompok Sirine JPL berasal dari populasi yang memiliki varians sama.

Selanjutnya dilakukan analisis varians (ANOVA) dimana untuk mengetahui apakah dua atau lebih mean populasi akan bernilai sama dengan menggunakan data dari sampel-sampel masingmasing populasi. Analisis juga dilakukan menggunakan SPSS 21. Hasilnya secara detil bisa dilihat pada tabel dibawah.

\section{Tabel 2 Hasil Output ANOVA}

\section{HASILUJI}

\begin{tabular}{|l|r|r|r|r|r|}
\hline & $\begin{array}{c}\text { Sum of } \\
\text { Squares }\end{array}$ & df & $\begin{array}{c}\text { Mean } \\
\text { Square }\end{array}$ & F & Sig. \\
\hline $\begin{array}{l}\text { Between } \\
\text { Groups }\end{array}$ & 5.815 & 4 & 1.454 & 3.051 & .019 \\
$\begin{array}{l}\text { Within } \\
\text { Groups }\end{array}$ & 62.415 & 131 & .476 & & \\
Total & 68.230 & 135 & & & \\
\hline
\end{tabular}

Sumber: Data Lapang Diolah, 2020

Dari tabel uji anova, SPSS memberi nilai statistik $\mathbf{F}=\mathbf{3 , 0 5 1}$ dengan derajat kebebasan $\mathrm{k}-1=$ $5-1=4$ dan $\mathrm{n}-\mathrm{k}=136-5=131$ dan $\mathbf{p}$-value $=$ 0,019 yang lebih kecil dari $\alpha=0,05$ maka menurut Uyanto (2009) bisa ditarik kesimpulan $\mathrm{H}_{\mathrm{o}}: \mu_{1}=\mu_{2}$ $=\mu_{3}=\mu_{4}=\mu_{5}$ ditolak dan menerima $\mathrm{H}_{1}: \mu_{1} \neq \mu_{2} \neq$ $\mu_{3} \neq \mu_{4} \neq \mu_{5}$. Artinya kelima Sirine JPL menghasilkan perhitungan suara dengan rata-rata level yang berbeda.
Pada hasil perhitungan diatas tampak hasil perhitungan semuanya ada di bawah standar dari Peraturan Menteri Perhubungan Nomor PM 44 Tahun 2018 tentang Persyaratan Teknis Peralatan Persinyalan Perkeretaapian yang mensyaratkan angka $115 \mathrm{db}$. Apabila dihitung secara rata-rata hasil perhitungan sebesar 83,4 db. Sedangkan ratarata margin antara hasil perhitungan dengan standar yang ditetapkan adalah 31,6 db. Angka ini akan berdampak pada jarak yang bisa dijangkau oleh sirine. Karena nilainya di bawah standar maka jarak suara sirine yang terdengar pada jarak tertentu semakin rendah. Hal ini menjadi catatan penting mengingat fungsi dari sirine ini cukup krusial sebagai peringatan dini pengguna jalan agar mengetahui bahwa akan ada kereta api yang akan melintas.

\subsubsection{Rambu yang Tidak Lagi Informatif}

Selain mendapatkan angka tingkat kekerasan suara sirine yang berada di bawah standar Peraturan Menteri Perhubungan Nomor PM 44 Tahun 2018 tentang Persyaratan Teknis Peralatan Persinyalan Perkeretaapian, ada temuan di lapangan yang berhasil didapatkan oleh peneliti. Silang andreas yang juga diwajibkan keberadaannya pada pintu perlintasan, kondisinya jauh dari sempurna.

\section{Gambar 6 Kondisi Silang Andreas Pada JPL 5 Kaligawe Resort 4.6 SMT}

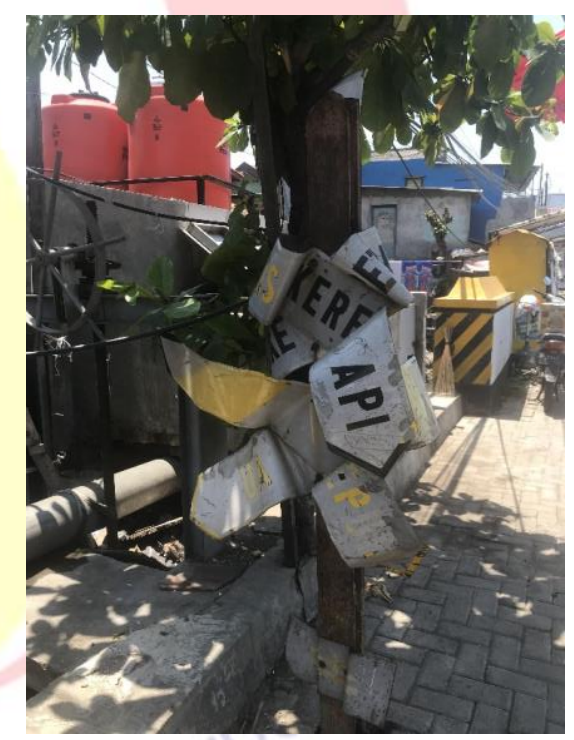

Sumber: Dokumentasi Lapang, 2020

Silang andreas diatas berada pada jalur dari arah Stasiun Tawang menuju pintu tol Kaligawe. Kondisinya tidak lagi cukup memberikan informasi 
kepada pengguna jalan mengenai jumlah jalur kereta api yang ada di depannya. Terlebih lagi, keberadaan silang andreas ini tertutup oleh asset Pemerintah Kota Semarang. Sehingga pengguna jalan tidak jelas melihat informasi ini. Padahal ini merupakan salah satu rambu yang berfungsi meningkatkan keselamatan pengguna jalan.

\subsection{Persepsi Pengguna Jalan Terhadap Kinerja Fasilitas Operasi di Bawah Resort 4.6 SMT}

Hasil pengamatan selama observasi memang menunjukkan angka di bawah standar. Namun, pengguna jalan menunjukkan kepuasan atas kinerja fasilitas operasi di lokasi penelitian. Ulin, pekerja tambak yang setiap harinya melewati pintu perlintasan sebidang menuturkan kesehariannya:

\section{"Tiap hari mas. Rumahnya deket situ soale."}

Ulin bisa lebih dari dua kali melewati pintu perlintasan JPL 5 Kaligawe untuk berangkat ke tempatnya bekerja. Sehingga dia tahu persis bagaimana penanda kereta api akan lewat ini beroperasi.

"Kedengeran. Kedenger jelas. Kalau (orang) daerah sini sudah pada tahu. Kalau pintu mau tertutup ada (suara) bel, sebelum dua menit lah itu (pintu) baru tertutup."

Menurut Ulin, fasilitas operasi berupa sirine terdengar jelas. Sirine ini akan berbunyi sebelum pintu perlintasan ditutup saat kereta api melintas. Sirine akan berbunyi sekiranya dua menit sebelum pintu benar-benar tertutup. Dewi seorang mahasiswa pada universitas ternama di Kota Semarang juga berpendapat yang sama.

"(Suara sirine) kenceng sekali. Iya bisa jadi penanda kalau pintu mau nutup."

Adli seorang karyawan swasta yang tiap hari hilir mudik melintasi pintu perlintasan JPL Hasanudin mengamini hal diatas. Menurutnya suara sirine ini terdengar jelas dan sangat bermanfaat keberadaannya.

"Pas pulang kerja capek banget. Kadang juga ngantuk. Kebetulan tiap hari lewat perlintasan Hasanudin. Pernah itu mau kebablasen. Untung suara sirine kenceng jadi keburu untuk ngerem."

Tidak hanya sirine, lampu silang datar menurut para pengguna jalan yang diwawancarai juga berfungsi dengan baik. Jalan Raya Kaligawe memang tidak terlalu terang pencahayaannya. Jadi keberadaan lampu silang datar ini bisa menjadi tanda bagi pengguna jalan. Seperti yang disampaikan oleh Rulita warga Sayung.

"Disitu kan ada lampu. Walaupun gelap (kondisi jalan), memang agak kurang penerangannya, cuma disitu kan ada lampu indikator. Jadi sangat terbantu. Siang juga nyala."

Mira, ibu rumah tangga yang sering berbelanja di Pasar Kokrosono yang berdekatan dengan JPL Kokrosono tidak pernah melihat lampu pada JPL ini padam. Tiap dia melewati JPL Kokrosono saat kereta akan melintas, lampu ini selalu menyala seolah memberi peringatan pada pengendara kalau pintu akan tertutup.

"Saya sering ke pasar (Kokrosono). Kalau lewat pintu perlintasan deket pasar situ pas kereta lewat, lampunya selalu nyala."

Kinerja dari fasilitas operasi perjalanan kereta api ternyata tidak menjamin keselamatan pengguna jalan dan kereta api. Buktinya dalam setahun terakhir, ada 7 kali kejadian pintu perlintasan tertabrak di JPL di bawah naungan Resort 4.6 SMT. Kealpaan pengguna jalan bisa jadi salah satu penyebabnya. Seperti yang diceritakan Minto, seorang nelayan dari Tambaklorok.

"Kalau kemarin yang kejadian bukan (warga) daerah sini. Eee Kemungkinan di bawah sadar. Hahaha. Kejadian yang kemarin itu yang nabrak perlintasan sampai patah itu kan malah pintu sudah tertutup lama. Itu udah tertutup, udah turun, terus ada orang (naik kendaraan) kenceng itu baru nabrak."

Kejadian yang diceritakan terjadi di JPL 5 Kaligawe. Seseorang yang diduga dibawah pengaruh alkohol menabarak pintu perlintasan hingga patah. Padahal menurut Minto, sirine dan lampu saat itu berfungsi dengan baik. Cerita kelalaian pengguna jalan tidak hanya berhenti disitu, Dewi mencoba menjelaskan cerita lucunya.

"Sering sih (mendengar kecelakaan di pintu perlintasan). Malah palang pintu dinaikin biar bisa lewat dahulu. Lumayan (lama pintu tertutup) sih soalnya."

Dari hasil wawancara dengan pengguna jalan, bisa ditarik benang merah bahwa menurut pengguna 
jalan fasilitas operasi di pintu perlintasan khususnya peringatan bagi pengguna jalan berfungsi dengan baik. Lampu menyala dengan jelas. Serta sirine terdengar dengan kencang walaupun secara teknis hasil uji menunjukkan angka di bawah standar yaitu $115 \mathrm{db}$.

\section{KESIMPULAN DAN SARAN}

Dari hasil pembahasan di bab sebelumnya, dapat ditarik kesimpulan diantaranya:

a) Kinerja fasilitas operasi berupa alat peringatan dini untuk pengguna jalan raya yaitu lampu silang datar pada JPL di JPL 5 Kaligawe, JPL 1B Layur, JPL Hasanudin, JPL Kokrosono, dan JPL BLPT berkinerja bagus. Ditempatkan sesuai PM 44 Tahun 2018 tentang Persyaratan Teknis Peralatan Persinyalan Perkeretaapian dan menyala saat pintu perlintasan akan tertutup. Namun untuk bunyi sirine, seluruh hasil pengujian di JPL 5 Kaligawe, JPL 1B Layur, JPL Hasanudin, JPL Kokrosono, dan JPL BLPT dibawah standar dari PM 44 Tahun 2018 tentang Persyaratan Teknis Peralatan Persinyalan Perkeretaapian sebesar $115 \mathrm{db}$.

b) Untuk persepsi pengguna jalan terhadap kinerja fasilitas operasi pada JPL di JPL 5 Kaligawe, JPL 1B Layur, JPL Hasanudin, JPL Kokrosono, dan JPL BLPT, merasa operasi berupa alat peringatan dini untuk pengguna jalan raya berfungsi dengan baik dan membantu pengguna jalan.

Berdasarkan pengalaman melaksanakan penelitian di lapangan mengenai Analisis Kinerja Fasilitas Operasi Perlintasan Sebidang, pada bagian ini peneliti hendak memberikan saran yang sekiranya dapat berguna bagi pemangku kebijakan serta penelitian selanjutnya.

a) Hasil pengujian tingkat kekerasan suara sirine semuanya di bawah standar yang diatur, peneliti merekomendasikan untuk melakukan pengujian di JPL lain. Mengingat keberadaan sirine ini sebagai salah satu alat peringatan yang memiliki fungsi krusial dalam menjamin keselamatan perjalanan kereta api.

b) Temuan di lapangan menunjukkan ada rambu yang kondisinya tidak lagi informatif. Peneliti merekomendasikan untuk melakukan perbaikan agar bisa berfungsi optimal.
Meskipun peneliti menginginkan kesempurnaan dalam penyusunan penelitian ini akan tetapi realitanya masih banyak kekurangan yang perlu peneliti perbaiki. Hal ini dikarenakan masih minimnya pengetahuan dan pengalaman peneliti. Oleh karena itu kritik dan saran yang membangun dari para pembaca sangat peneliti harapkan sebagai bahan evaluasi untuk kedepannya.

\section{REFERENSI}

[1] Arikunto, S. 2010. Prosedur Penelitian Suatu Pendekatan Praktik. Jakarta: Rineka Cipta.

[2] Harahap, Juliansyah. 2016. Penentuan Tingkat Kebisingan Pada Area Pengolahan Sekam Padi, Siltstone Crusher, Cooler Dan Power Plant Pada Pt Lafarge Cement IndonesiaLhoknga Plant. Elkawnie: Journal of Islamic Science and Technology Vol. 2, No.2, Desember $2016 \quad$ (www.jurnal.arraniry.com/index.php/elkawnie)

[3] Harinaldi. 2005. Prinsip-Prinsip Statistik Untuk Teknik dan Sains. Jakarta: Penerbit Erlangga

[4] Hasan, M. Iqbal. 2002. Pokok-pokok Materi Metodologi Penelitian dan Aplikasinya. Bogor: Ghalia Indonesia.

[5] Republik Indonesia. 2007. Undang-Undang Nomor 23 Tahun 2007 tentang Perkeretaapian.

[6] Republik Indonesia. 2009. Peraturan Pemerintah Nomor 56 Tahun 2009 tentang Penyelenggaraan Perkeretaapian.

[7] Republik Indonesia. 2009. Peraturan Pemerintah Nomor 72 Tahun 2009 tentang Lalu Lintas dan Angkutan Kereta Api.

[8] Republik Indonesia. 2009. Undang-Undang Nomor 22 Tahun 2009 tentang Lalu Lintas dan Angkutan Jalan.

[9] Republik Indonesia. 2005. Peraturan Direktur Jenderal Perhubungan Darat Nomor: SK.770/KA.401/DRJD/2005 tentang Pedoman Teknis Perlintasan Sebidang Antara Jalan Dengan Jalur Kereta Api.

[10] Soedojo. 2004. Fisika Dasar. Yokyakarta:CV Andi Offset.

[11] Sugiyono. 2015. Metode Penelitian Kombinasi (Mix Methods). Bandung: Alfabeta.

[12] Su'udi, Ahmad. 2010. Reduksi Bising Motor Diesel Menggunakan Partial Enclosure. Jurnal Mechanical, Volume 1, Nomor 1, Maret 2010.

[13] Uyanto, Stanislaus S. 2009. Pedoman Analisa Data dengan SPSS. Jakarta: Graha Ilmu 
[14] Wahidmurni. 2017. Pemaparan Metode Penelitian Kuantitatif. Malang: UIN Maulana Malik Ibrahim Malang.

[15] Yasid, Abdul, Yushardi, Handayani, Rif'ati Dina. 2015. Pengaruh Frekuensi Gelombang Bunyi Terhadap Perilaku Lalat Rumah
(Musca domestica). Jurnal Pembelajaran Fisika, Vol. 5 No. 2, September 2016, hal 190 - 196 